\title{
Modulation of endogenous pathways enhances bioethanol yield and productivity in Escherichia coli
}

Neha Munjal ${ }^{1}$, Anu Jose Mattam', Dibyajyoti Pramanik ${ }^{1}$, Prem Shankar Srivastava ${ }^{2}$ and Syed Shams Yazdani ${ }^{{ }^{*}}$

\begin{abstract}
Background: E. coli is a robust host for various genetic manipulations and has been used commonly for bioconversion of hexose and pentose sugars into valuable products. One of the products that E. coli make under fermentative condition is ethanol. However, availability of limited reducing equivalence and generation of competing co-products undermine ethanol yield and productivity. Here, we have constructed an E. coli strain to produce high yield of ethanol from hexose and pentose sugars by modulating the expression of pyruvate dehydrogenase and acetate kinase and by deleting pathways for competing co-products.
\end{abstract}

Results: The availability of reducing equivalence in E. coli was increased by inducing the expression of the pyruvate dehydrogenase $(\mathrm{PDH})$ operon under anaerobic condition after replacement of its promoter with the promoters of IdhA, frdA, pfIB, adhE and gapA. The SSY05 strain, where PDH operon was expressed under gapA promoter, demonstrated highest PDH activity and maximum improvement in ethanol yield. Deletion of genes responsible for competing products, such as lactate (IdhA), succinate ( $f r d A)$, acetate (ack) and formate $(p f \mid B)$, led to significant reduction in growth rate under anaerobic condition. Modulation of acetate kinase expression in SSY09 strain regained cell growth rate and ethanol was produced at the maximum rate of $12 \mathrm{mmol} / \mathrm{l} / \mathrm{h}$ from glucose. The resultant SSY09(pZSack) strain efficiently fermented xylose under microaerobic condition and produced $25 \mathrm{~g} / \mathrm{l}$ ethanol at the maximum rate of $6.84 \mathrm{mmol} / \mathrm{l} / \mathrm{h}$ with $97 \%$ of the theoretical yield. More importantly, fermentation of mixture of glucose and xylose was achieved by SSY09(pZSack) strain under microaerobic condition and ethanol was produced at the maximum rate of $0.7 \mathrm{~g} / / \mathrm{h}$ ( $15 \mathrm{mmol} / \mathrm{l} / \mathrm{h})$, respectively, with greater than $85 \%$ of theoretical yield.

Conclusions: The E. coli strain SSY09(pZSack) constructed via endogenous pathway engineering fermented glucose and xylose to ethanol with high yield and productivity. This strain lacking any foreign gene for ethanol fermentation is likely to be genetically more stable and therefore should be tested further for the fermentation of lignocellulosic hydrolysate at higher scale.

Keywords: Escherichia coli, Endogenous pathways, Promoter engineering, Pyruvate dehydrogenase, Acetate kinase, Ethanol

\section{Background}

We are largely dependent upon fossil fuels for fulfilling our energy requirement [1]. Fuels from renewable sources, such as agricultural and forest residues, hold promise in reducing our dependence on fossil fuel without competing with food. The agricultural and forestry waste mostly consist of lignocellulose, which is made-up

\footnotetext{
*Correspondence: shams@icgeb.res.in

'Synthetic Biology and Biofuel Group, International Centre for Genetic Engineering and Biotechnology (ICGEB), Aruna Asaf Ali Marg, New Delhi 110067, India

Full list of author information is available at the end of the article
}

of highly structured cellulose surrounded by hemicellulose and lignin [2]. In principle, it is possible to breakdown lignocellulose into the monosaccharides and ferment them into ethanol. However, cost associated with this process is a major hurdle in terms of commercial application [3]. One of the key advancement in the economy of ethanol production from lignocellulosic biomass will be to efficiently ferment both hexose and pentose sugars released after hydrolysis of lignocellulose into ethanol. Unfortunately, the conventional microorganisms used for ethanol fermentation, e.g., 
Saccharomyces cerevisiae and Zymomonas mobilis, do not have the capability to utilize pentose sugars [4]. Attempts have been made to transfer genes for pentose degradation pathway from other organisms into $S$. cerevisiae [5] and Z. mobilis [6]. However, the disadvantages associated with foreign gene expression at large scale like instability, toxicity, containment, etc., prevent its wide usage. Escherichia coli, on the other hand, has the ability to ferment both hexose and pentose sugars and is being used to produce ethanol by various genetic manipulation [4]. The genetic manipulation of $E$. coli that does not involve introduction of foreign gene has been attempted with some successes and these technologies certainly have advantages in the long-term genetic stability of the engineered strain $[7,8]$.

Under anaerobic condition, E. coli produces ethanol through a pathway that involves pyruvate formate lyase (PFL), which converts pyruvate into acetyl-CoA and formate (Figure 1) [9]. However, this pathway is not redox balanced because in the process of metabolizing one mole of glucose into ethanol, four moles of NADH are consumed while only two moles of NADH are produced (Reaction (i)-(iii)).

$$
\begin{aligned}
& \text { Glucose }+2 \mathrm{ADP}+2 \mathrm{NAD}^{+} \stackrel{\text { Glycolysis }}{\rightarrow} 2 \text { Pyruvate } \\
& +2 \mathrm{ATP}+2 \mathrm{NADH}
\end{aligned}
$$

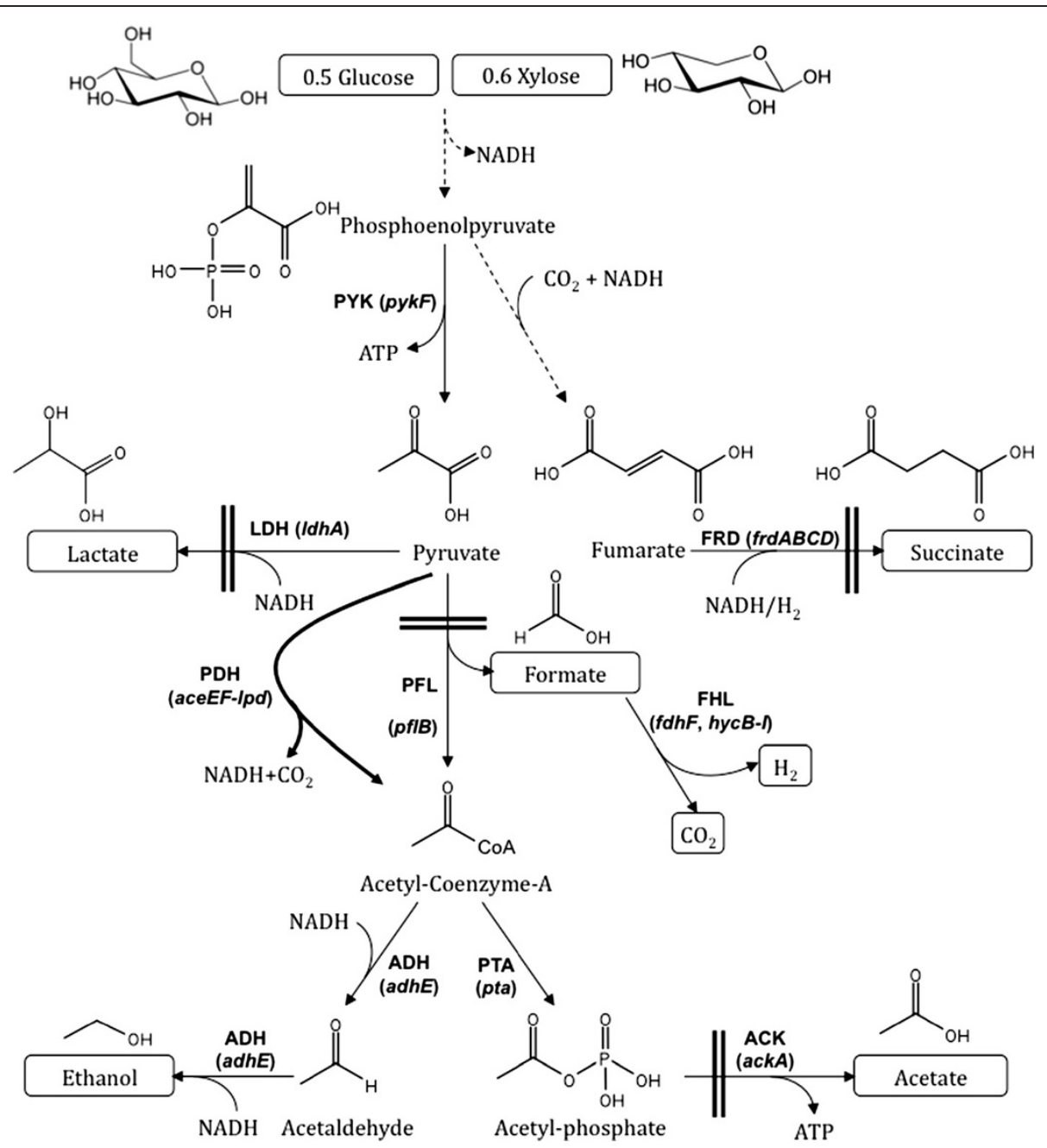

Figure 1 Central metabolic pathways of $E$. coli functional under anaerobic condition during glucose and xylose fermentation. Relevant genes and corresponding enzymes are shown. Pyruvate dehydrogenase (PDH) operon was expressed under anaerobic condition via promoter replacement and is represented as thick line. The competing pathways to ethanol were blocked as shown by two parallel bars. Broken arrows represent multiple reactions of a pathway. Extracellular metabolites are placed in boxes. Abbreviations are as follows: ADH, acetaldehyde/alcohol dehydrogenase; ACK, acetate kinase; FHL, formate hydrogen-lyase; FRD, fumarate reductase; LDH, lactate dehydrogenase; PDH, pyruvate dehydrogenase; PFL, pyruvate formate-lyase; PTA, phosphate acetyltransferase; PYK, pyruvate kinase. 
2 Pyruvate $\stackrel{\text { PFL }}{\rightarrow} 2$ Acetyl - CoA +2 Formate

$$
\begin{aligned}
& 2 \text { Acetyl }-\mathrm{CoA}+4 \mathrm{NADH} \stackrel{\mathrm{ADH}}{\rightarrow} 2 \text { Ethanol } \\
& \quad+4 \mathrm{NAD}^{+}
\end{aligned}
$$

This redox imbalance would negatively impact the yield of ethanol. However, there is an alternate pathway exists where converting glucose into ethanol or butanol is a redox balance process. Here pyruvate in converted into acetyl-CoA and $\mathrm{CO}_{2}$ via pyruvate dehydrogenase complex (PDH) and in the process one molecule of NADH is produced (Reaction (iv)) [10].

$$
\begin{aligned}
& 2 \text { Pyruvate }+2 \mathrm{NAD}^{+} \stackrel{\text { PDH }}{\rightarrow} 2 \text { Acetyl }-\mathrm{CoA} \\
& \quad+2 \mathrm{CO}_{2}+2 \mathrm{NADH}
\end{aligned}
$$

However, expression of PDH is repressed under anaerobic condition and remains active in the aerobically growing cells [10]. To activate the expression of PDH under anaerobic condition, the promoter of $\mathrm{PDH}$ should be replaced with the one that is highly active under anaerobic condition. One such study showed that replacing PDH promoter with PFL promoter has enhanced the expression of PDH under anaerobic condition and increased the yield of ethanol [8]. However, ethanol productivity was significantly lower in this study indicating sub-optimal flux through the PDH pathway.

In the study reported here, we have performed a systematic study of PDH expression under anaerobic condition by replacing its promoter with a number of promoters of the genes that are expressed at high level under anaerobic condition. A novel promoter-PDH operon combination was selected based on higher PDH enzyme activity and bioalcohol production and deletion mutants were generated to stop carbon flow to the competing byproducts. With the knowledge gained from the growth rate of various deletion mutants, we found a new way to improve cell growth and ethanol productivity by modulating expression of acetate kinase in the engineered cells. We further demonstrate that the engineered $E$. coli strain grown under microaerobic condition utilized xylose with the yield higher than reported before $[7,8]$. Furthermore, to our knowledge we show for the first time fermentation of mixture of glucose and xylose into ethanol by the engineered $E$. coli strain without having any foreign gene for the ethanol production.

\section{Results and discussion}

Promoter replacement of pyruvate dehydrogenase (PDH) operon enhances its activity and ethanol yield under anaerobic condition

Ethanol production in E. coli through pyruvate formate lyase (PFL) pathway is short of reducing equivalent to achieve a theoretical maximum yield via fermentation of pentose and hexose sugars (Figure 1). Therefore, wild type E. coli typically produces mixed acids under fermentative condition with only fraction of carbon goes towards ethanol. The redox balance for homoethanol production may be achieved upon optimal activation of pyruvate dehydrogenase (PDH) pathway under anaerobic condition (Figure 1). The operon encoding PDH complex is usually repressed under anaerobic condition through global repressor binding to its promoter. To prevent this repression, we decided to replace the promoter of PDH operon with the promoter of the genes known to express under anaerobic condition. In the absence of information in the literature regarding relative strength of promoters of the genes expressed under anaerobic condition, we selected promoters of five genes, frdA, ldhA, pflB, adhE and gapA, and replaced native promoter of PDH operon as mentioned in the methods section. The resultant transformants were verified by internal template based and external host chromosome based primers and were designated as SSY01 to SSY05 for $\mathrm{P}_{\text {ldhA }} \mathrm{PDH}, \mathrm{P}_{\text {frdA }} \mathrm{PDH}, \mathrm{P}_{\text {pflB }} \mathrm{PDH}, \mathrm{P}_{\text {adhe }} \mathrm{PDH}$ and $\mathrm{P}_{\text {ga- }}$ ${ }_{\mathrm{pA}} \mathrm{PDH}$ promoters, respectively (Table 1).

The engineered cells were grown under anaerobic condition in defined medium for different time intervals and used for measuring pyruvate dehydrogenase (PDH) activity. The results indicated maximum PDH activity between 18-24 h of anaerobic growth (Figure 2A). Except SSY01 strain $\left(\mathrm{P}_{\text {ldhA }} \mathrm{PDH}\right)$, all promoter engineered strains showed significant improvement in PDH activity over wild type strain. This result was intriguing since pdh gene in Geobacillus thermoglucosidasius under the control of $l d h$ promoter was shown to have positive effect on ethanol production [12], indicating higher flux through PDH pathway in this strain due to higher PDH activity. We therefore compared ethanol production capabilities of all the engineered strains to assess flux towards PDH pathway.

The engineered strains SSY01 to SSY05 along with wild type $E$. coli $\mathrm{B}$ were grown in defined medium in filled Hungate tube with $2.5 \mathrm{~g} / \mathrm{l}$ of either glucose or xylose as carbon source and cultures were analyzed for production of ethanol at different time intervals. Most engineered strains utilized complete $13.9 \mathrm{mM}$ glucose in $12 \mathrm{~h}$ and produced ethanol in the range of $11.7 \mathrm{mM}$ (for SSY01) to $17 \mathrm{mM}$ (for SSY05) as compared to E. coli B which produced $12.2 \mathrm{mM}$ ethanol. It took $24 \mathrm{~h}$ for the E. coli strains to utilize xylose $(17 \mathrm{mM}$ ) with $0 \%$ (for 
Table 1 Strains, plasmids and primers used in the study

\begin{tabular}{|c|c|c|}
\hline Name & Description & Reference or Source \\
\hline \multicolumn{3}{|l|}{ Strains } \\
\hline E. coli B & F- & CGSC \#2507 \\
\hline SSY01 & $\begin{array}{l}\text { E. coli B, } \triangle \mathrm{PDH} \text {-promoter::FRT-kan-FRT-IdhA gene promoter; } \\
\text { promoter of } p d h \text { gene replaced with promoter of IdhA gene }\end{array}$ & This study \\
\hline SSYO2 & E. coli B, $\triangle \mathrm{PDH}$-promoter:FRT-kan-FRT-frdA gene promoter & This study \\
\hline SSYO3 & E. coli B, $\triangle \mathrm{PDH}$-promoter:FRT-kan-FRT-pflB gene promoter & This study \\
\hline SSY04 & E. coli B, $\triangle \mathrm{PDH}$-promoter::FRT-kan-FRT-adhE gene promoter & This study \\
\hline SSY05 & E. coli B, $\triangle \mathrm{PDH}$-promoter::FRT-kan-FRT-gapA gene promoter & This study \\
\hline SSY06 & SSY05 $\Delta / d h A:: F R T-k a n-F R T$; deletion mutant for IdhA gene in SSY05 host & This study \\
\hline SSY07 & SSY06 $\Delta$ frdA:FRT-kan-FRT; deletion mutant for frdA gene in SSY06 host & This study \\
\hline SSY08 & SSY07 $\triangle a c k A .: F R T$-kan-FRT; deletion mutant for ackA gene in SSY07 host & This study \\
\hline SSYO9 & SSY08 $\triangle$ pflB::FRT-kan-FRT; deletion mutant for pflB gene in SSY08 host & This study \\
\hline \multicolumn{3}{|l|}{ Plasmids } \\
\hline pUC19 & bla, cloning vector & \\
\hline pKD4 & bla, FRT-kan-FRT & CGSC \#7632 \\
\hline pKD46 & bla, y $\beta$ exo (red recombinase), temperature-conditional replicon & CGSC \#7739 \\
\hline pCP20 & bla, flp, temperature-conditional replicon & CGSC \#7629 \\
\hline pSSY01 & FRT-kan-FRT sequence from pKD4 was cloned into pUC19 at EcoRI and BamHI sites & This study \\
\hline pSSY02 & IdhA gene promoter from E. coli B was cloned into pSSY01 at BamHI and Hindlll site & This study \\
\hline pSSY03 & frdA gene promoter from E. coli B was cloned into pSSY01 at BamHI and HindllI sites & This study \\
\hline pSSY04 & pflB gene promoter from E. coli B was cloned into pSSY01 at BamHI and Hindlll sites & This study \\
\hline pSSY05 & adhE gene promoter from E. coli B was cloned into pSSYO1 at BamHI and Hindlll sites & This study \\
\hline pSSY06 & gapA gene promoter from E. coli B was cloned into pSSYO1 at BamHI and Hindlll sites & This study \\
\hline pZSblank & $P_{\text {Ltet01 }}$ expression vector, pSC101*origin, $\mathrm{Cm}^{\mathrm{R}}$ & {$[11]$} \\
\hline pZS*mcs & multiple cloning site derived from pET28a(+) cloned in pZSblank & This study \\
\hline pZSack & ack gene cloned in $\mathrm{pZS}^{*} \mathrm{mcs}$ vector & This study \\
\hline \multicolumn{3}{|l|}{ Primers } \\
\hline FRT-kan-FRT-F & GGAGAGAATTCGTGTAGGCTGGAGCTGCTTC & This study \\
\hline FRT-kan-FRT-R & GGAGAGGATCCATATGAATATCCTCCTTAG & This study \\
\hline IdhA promoter-F & TCGGGATCCGCAAGCTGACAATCTCCC & This study \\
\hline IdhA promoter-R & ACTCAAGCTTAAGACTTTCTCCAGTGATGTTG & This study \\
\hline frdA promoter-F & TGCGGATCCATCAAACAGCGGTGGGCAG & This study \\
\hline frdA promoter-R & CCCAAGCTTGACATTCCTCCAGATTGTTT & This study \\
\hline pflB promoter-F & TCGGGATCCAACCATGCGAGTTACGGGCCTATAA & [8] \\
\hline pflB promoter-R & CCCAAGCTTGTGCCTGTGCCAGTGGTTGCTGTGA & This study \\
\hline adhE promoter-F & CGCGGATCCCCGGATAATGTTAGCCATAA & This study \\
\hline adhE promoter-R & CCCAAGCTTAATGCTCTCCTGATAATGTTA & This study \\
\hline gapA promoter-F & CGCGGATCCGATTCTAACAAAACATTAACAC & This study \\
\hline gapA promoter-R & CCCAAGCTTATATTCCACCAGCTATTTGT & This study \\
\hline $\mathrm{H} 1$ & CTCCTTTCCTACGTAAAGTCTACATTTGTGCATAGTTACAACTTTGTGTAGGCTGGAGCTGCTTC & [8] \\
\hline $\mathrm{H} 2 \_I d h A$ & GCGAGTTTCGATCGGATCCACGTCATTTGGGAAACGTTCTGACATAAGACTTTCTCCAGTGATGTTG & This study \\
\hline H2_adhE & GCGAGTTTCGATCGGATCCACGTCATTTGGGAAACGTTCTGACATAATGCTCTCCTGATAATGTT & This study \\
\hline H2_gapA & GCGAGTTTCGATCGGATCCACGTCATTTGGGAAACGTTCTGACATATATTCCACCAGCTATTTGT & This study \\
\hline $\mathrm{H} 2 \_$frdA & GCGAGTTTCGATCGGATCCACGTCATTTGGGAAACGTTCTGACATGACATTCCTCCAGATTGTTा & This study \\
\hline
\end{tabular}


Table 1 Strains, plasmids and primers used in the study (Continued)

\begin{tabular}{lll}
\hline H2_pflB & GCGAGTTTCGATCGGATCCACGTCATTTGGGAACGTTCTGACATGTAACACCTACCTTCTGTTG & {$[8]$} \\
v-PDH-F & CTGTGATATAGAAGAC & This study \\
v-PDH-R & TGATGGTTGAAGATGAGTTG & This study \\
pET28mcs-F & CGGGATCCGAATTCGATACCTG & This study \\
pET28mcs-R & CTGACGCGTGTTAACAGCTTCCTTTCGGGTTTG & This study \\
pZS-ack-F & GATCGGATCCATGTCGAGTAAGTTAGTACTGGT & This study \\
pZS-ack-R & TCGAGTCGACTCAGGCAGTCAGGCGGCTC & This study \\
\hline
\end{tabular}

Note: Homologous region for recombination is in italics and the enzyme sites are underlined.

SSY05) to 20\% (for E. coli B and SSY01) residual sugar left at the end. Ethanol from xylose was produced in the range of $13 \mathrm{mM}$ (for SSY01) to $21 \mathrm{mM}$ (for SSY05) as compared to wild type $E$. coli B that produced $13 \mathrm{mM}$ ethanol. These observations indicated that SSY01 with $\mathrm{P}_{\text {ldh }} \mathrm{PDH}$ genotype behaved similar to wild type E. coli in terms of ethanol production as against Geobacillus thermoglucosidasius where it improved ethanol production [12]. Possible explanation of these observations could be that $l d h$ promoter in $E$. coli was either relatively weaker or regulated through complex mechanism under anaerobic condition. This hypothesis needs further exploration. Other engineered strains showed higher ethanol production as compared to the wild type strain. SSY05 performed best among all the engineered stains and therefore was considered for further strain improvement. Our approach of first optimizing the flux towards the PDH pathway through promoter engineering in the wild type strain before any deletion in the competing pathway, as against the previous report where the flux through PDH pathway was enforced by first deleting the competing pathway [8], had an advantage of finding optimal flux through $\mathrm{PDH}$ pathway even in presence of competing PFL pathway that is considered essential under anaerobic condition [9]. This was likely to lower the adverse impact on cell growth upon $p f l B$ deletion.

\section{Deletion of competing pathways improves ethanol yield in the engineered SSY05 strain}

Though the promoter engineered SSY05 strain exhibited significant enhancement in the ethanol level as compared to the wilde type strain, it still produced considerable amount of competing co-products such as lactate, succinate, acetate and formate (Table 2). To further improve ethanol yield, we introduced deletion in the genes for lactate dehydrogenase $(l d h A)$, fumarate reductase $(\operatorname{frd} A)$, acetate kinase $(a c k)$ and pyruvate formate lyase $(p f l B)$ responsible for the formation of lactate, succinate, acetate and formate, respectively, to obtain SSY06 ( $\mathrm{P}_{\text {gapA }}$ PDH $\Delta l d h A)$, SSY07 ( $\mathrm{P}_{\text {gapA }}$ PDH $\Delta l d h A \Delta$ frdA), SSY08 $\left(\mathrm{P}_{\text {gapA }}\right.$ PDH $\Delta l d h A \Delta$ frdA $\Delta$ ack) and SSY09 ( $\mathrm{P}_{\text {gapA }}$ PDH
$\Delta l d h A \Delta$ frdA $\Delta$ ack $\Delta$ pflB) strains (Table 1). When grown in defined medium under anaerobic condition, SSY06 and SSY07 grew normally (Table 2), SSY08 grew very slowly and SSY09 did not grow at all. This observation indicated that deletion of ack had deleterious impact on cell growth, possibly due to corresponding depletion of ATP pool, and further deletion of $p f l B$ had a cumulative effect on adverse impact even after the expression of parallel PDH pathway. Deletion of ack and pflB leading to adverse impact on cell growth under anaerobic condition has also been observed earlier $[9,13]$. To regain the cell growth, we introduced ack gene through a very low copy plasmid in SSY09 strain. We found significant improvement in cell growth upon transformation with the plasmid containing ack gene (pZSack) as compared to the strain transformed with the control plasmid (pZS*mcs) even without addition of an inducer, indicating minor leaky expression of ack gene (Figure $3 \mathrm{~A}$ and $3 \mathrm{~B}$ ). Acetate level in uninduced SSY09(pZSack) strain was less than $50 \%$ of the wild type strain. We further tested ethanol-producing capability of the engineered strains at the bioreactor level under controlled environmental condition.

Comparison of engineered strains for ethanol production at the bioreactor level in defined medium

When grown in a bioreactor, wild type E. coli B produced ethanol at the yield of 0.65 and 0.61 mmol per mmol of glucose and xylose, respectively, in defined medium under anaerobic condition as against the theoretical maximum yield of 2 and $1.67 \mathrm{mmol}$ per mmol of these sugars due to generation of competing coproducts (Figure $4 \mathrm{~A}$ and $4 \mathrm{~B}$, Table 2). The promoter engineered SSY05 strain showed 10\% higher ethanol yield as compared to wild type strain, indicating favourable redox balance towards ethanol production (Table 2). Successive deletion made in the competing pathways to generate SSY06, SSY07 and SSY09(pZSack) strains resulted in corresponding increase in ethanol and decrease in co-product yield (Table 2). SSY09(pZSack) strain grown in defined medium with $20 \mathrm{~g} / \mathrm{l}$ glucose 


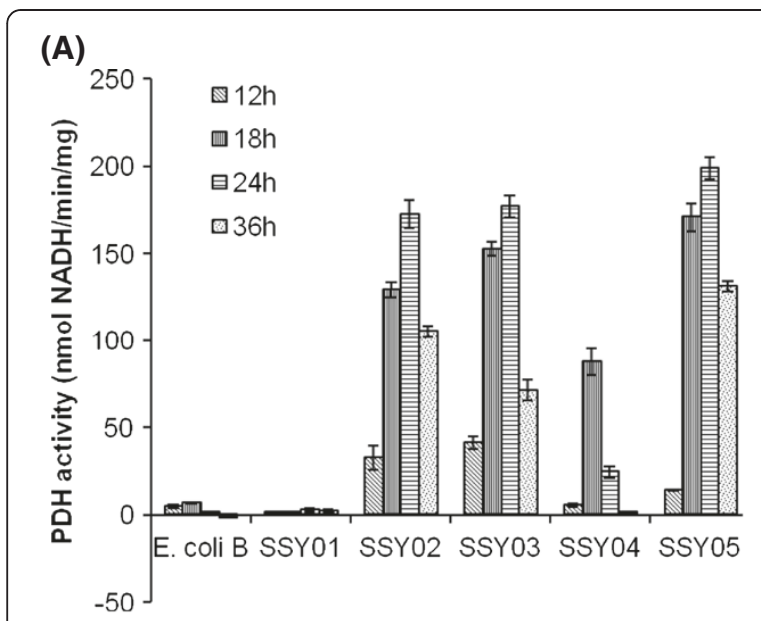

(B)
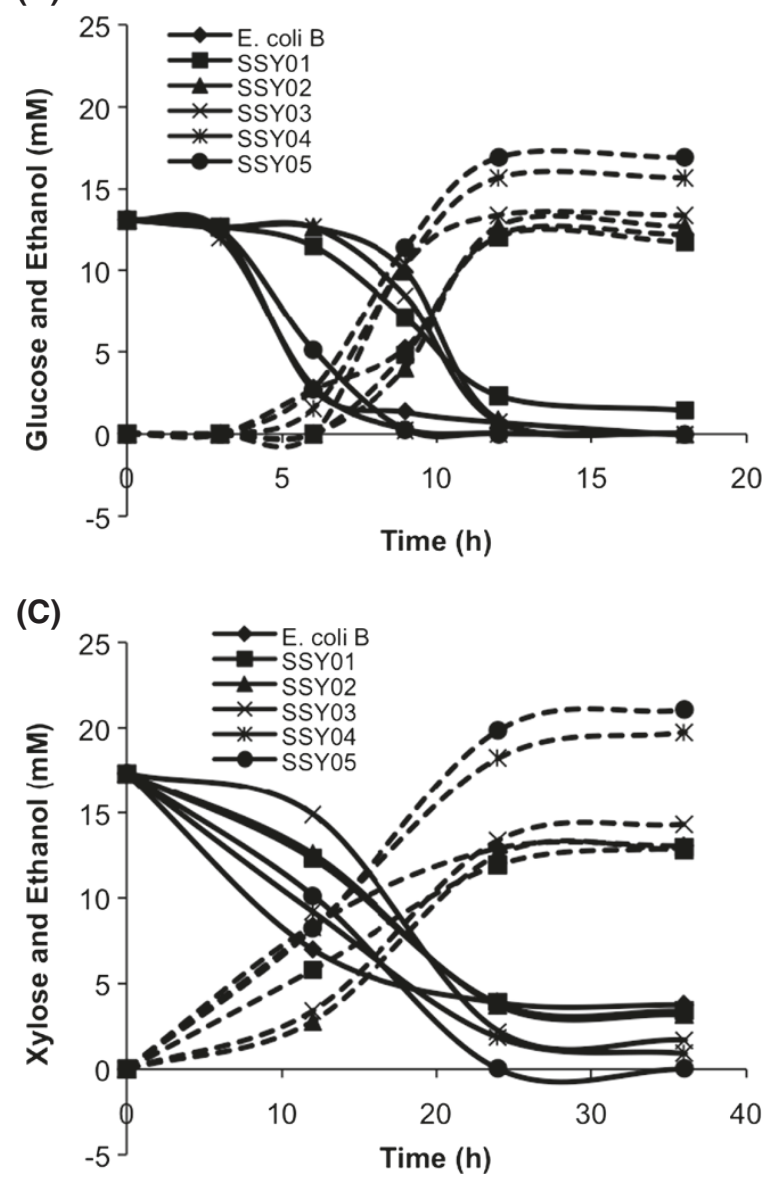

Figure 2 Functional characterization of promoter engineered $E$. coli B strains (SSY01-05, see Table 1 for genotype). Effect of PDH operon promoter replacement on (A) pyruvate dehydrogenase activity and (B) ethanol production was monitored. Cells were grown anaerobically in completely filled Hungate tubes and were harvested and permeabilized to measure PDH activity. The supernatant of the culture was used to analyze metabolite concentration via HPLC. Strain description for changed PDH

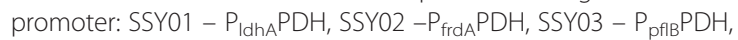
SSYO4 - $P_{\text {adhE }} P D H$, SSYO5 - $P_{\text {gapA }} P D H$. or xylose at the bioreactor level produced ethanol at $83 \%$ or $68 \%$ of theoretical maximum yield, respectively (Figure 4C and 4D, Table 2). However, $\sim 25 \%$ of substrate remained unutilized at $\sim 200$ hrs of fermentation and ethanol was produced at the low volumetric productivity of $1.6-1.9 \mathrm{mmol} / \mathrm{l} / \mathrm{h}$. This observation indicated that the engineered PDH pathway possibly could not fully complement the loss the PFL pathway.

\section{Comparison of engineered strains for ethanol production at the bioreactor level in complex medium}

To improve the growth, substrate utilization and ethanol production rate, we grew the engineered cells in LB medium with $50 \mathrm{~g} / \mathrm{l}$ substrate. The wild type strain produced lactate and acetate as major metabolic products with ethanol produced only at the yield of 0.31 and $0.79 \mathrm{mmol}$ per mmol glucose and xylose, respectively (Figure 5A and $5 \mathrm{~B}$, Table 2). Remarkable improvement in growth rate was observed in the case of SSY09(pZSack) strain when grown in complex medium. The growth profile indicated that complex media served as nutrient supplement for achieving initial cell growth, and sugar consumption occurred after the growth cycle (Figure 5C and 5D). This strategy allowed the cells to overcome the growth limitation arose due to $p f l B$ deletion. Ethanol was produced at the rate of $12.34 \mathrm{mmol} / \mathrm{l} / \mathrm{h}$ with $95 \%$ of the theoretical yield using glucose as carbon source (Figure 5C, Table 2). The final ethanol concentration achieved was $21 \mathrm{~g} / \mathrm{l}(457 \mathrm{mM})$ from $46 \mathrm{~g} / \mathrm{l}(255 \mathrm{mM})$ glucose in $80 \mathrm{~h}$ (Figure $5 \mathrm{C}$ ).

The xylose utilization rate, however, was still slow in the SSY09(pZSack) strain with 25\% xylose remained unutilized after $260 \mathrm{~h}$ of fermentation and ethanol produced only at the rate of $1.67 \mathrm{mmol} / \mathrm{l} / \mathrm{h}$ (Figure $5 \mathrm{C}$, Table 2). This was because xylose fermentation into ethanol leads to generation of only 0.67 ATP per xylose as against glucose fermentation where 2 ATPs per glucose are generated. There was a slight increase in xylose utilization rate when $\mathrm{pH}$ of the cultivation was maintained at 6.3 (data not shown), possibly due to higher activity of a xylose/proton symporter [14]. To further enhance the growth rate of the cells, we introduced a microaerobic condition by passing compressed air in the headspace of bioreactor at a very slow flow rate as mentioned in the methods section. Microaerobic condition would allow extra ATP for cell growth through partial activation of TCA cycle. Cell growth and xylose utilization rate improved significantly with $50 \mathrm{~g} / \mathrm{l}$ xylose utilized in $115 \mathrm{~h}$ and $25 \mathrm{~g} / \mathrm{l}$ ethanol produced at the rate of $6.84 \mathrm{mmol} / \mathrm{l} / \mathrm{h}$ with $97 \%$ of the maximum theoretical yield (Figure 6A). This yield of ethanol from xylose was higher than those reported in the literature from the engineered $E$. coli without the foreign genes $[7,8]$. 
Table 2 Fermentation parameters for cell growth, sugar utilization and product synthesis at the bioreactor level

\begin{tabular}{|c|c|c|c|c|c|c|c|c|c|c|c|}
\hline \multirow[t]{2}{*}{ Sugar } & \multirow[t]{2}{*}{ Strain } & \multirow{2}{*}{$\begin{array}{l}\text { Medium+Sugar } \\
\text { Conc. }^{\text {a }}\end{array}$} & \multicolumn{6}{|c|}{ Product Yield (mmol per mmol sugar) } & \multirow{2}{*}{$\begin{array}{c}\text { \% Theoretical } \\
\text { yield of } \\
\text { ethanol }^{b}\end{array}$} & \multicolumn{2}{|c|}{ Max ethanol productivity } \\
\hline & & & Cells & Succinate & Lactate & Formate & Acetate & Ethanol & & $\begin{array}{c}\text { Specific } \\
(\mathrm{mmol} / \mathrm{g} / \mathrm{h})\end{array}$ & $\begin{array}{l}\text { Volumetric } \\
(\mathrm{mmol} / \mathrm{l} / \mathrm{h})\end{array}$ \\
\hline \multirow[t]{7}{*}{ Glucose } & E. coli B & $\begin{array}{c}\text { Defined } \\
\text { medium }+20 \mathrm{~g} / \mathrm{l}\end{array}$ & 0.36 & 0.11 & 0.42 & 1.19 & 0.51 & 0.65 & 32 & 4.82 & 4.72 \\
\hline & SSY05 & $\begin{array}{c}\text { Defined } \\
\text { medium }+20 \mathrm{~g} / \mathrm{l}\end{array}$ & 0.40 & 0.14 & 0.13 & 0.98 & 0.42 & 0.84 & 42 & 5.76 & 6.19 \\
\hline & SSY06 & $\begin{array}{c}\text { Defined } \\
\text { medium }+20 \mathrm{~g} / \mathrm{l}\end{array}$ & 0.42 & 0.14 & 0.02 & 1.15 & 0.53 & 0.96 & 48 & 6.42 & 6.91 \\
\hline & SSY07 & $\begin{array}{c}\text { Defined } \\
\text { medium }+20 \mathrm{~g} / \mathrm{l}\end{array}$ & 0.46 & 0.01 & 0.03 & 1.16 & 0.46 & 1.08 & 54 & 4.85 & 5.97 \\
\hline & $\begin{array}{l}\text { SSY09 } \\
\text { (pZSack) }\end{array}$ & $\begin{array}{c}\text { Defined } \\
\text { medium }+20 \mathrm{~g} / \mathrm{l}\end{array}$ & 0.25 & 0.00 & 0.00 & 0.00 & 0.12 & 1.67 & 83 & 4.00 & 1.62 \\
\hline & E. coli B & LB medium+50 g/l & 0.23 & 0.07 & 0.78 & 0.57 & 0.37 & 0.31 & 16 & 6.15 & 3.06 \\
\hline & $\begin{array}{c}\text { SSY09 } \\
\text { (pZSack) }\end{array}$ & LB medium $+50 \mathrm{~g} / \mathrm{l}$ & 0.16 & 0.01 & 0.01 & 0.03 & 0.07 & 1.89 & 95 & 20.03 & 12.34 \\
\hline \multirow[t]{5}{*}{ Xylose } & E. coli B & $\begin{array}{c}\text { Defined } \\
\text { medium }+20 \mathrm{~g} / \mathrm{l}\end{array}$ & 0.34 & 0.17 & 0.00 & 1.21 & 0.80 & 0.61 & 36 & 2.46 & 1.54 \\
\hline & $\begin{array}{l}\text { SSY09 } \\
\text { (pZSack) }\end{array}$ & $\begin{array}{c}\text { Defined } \\
\text { medium+20 g/l }\end{array}$ & 0.24 & 0.01 & 0.02 & 0.00 & 0.14 & 1.09 & 68 & 6.15 & 1.96 \\
\hline & E. coli B & LB medium $+50 \mathrm{~g} / \mathrm{l}$ & 0.20 & 0.10 & 0.05 & 0.30 & 0.70 & 0.79 & 47 & 3.13 & 1.90 \\
\hline & $\begin{array}{c}\text { SSY09 } \\
\text { (pZSack) }\end{array}$ & LB medium+50 g/l & 0.18 & 0.02 & 0.01 & 0.03 & 0.26 & 0.91 & 55 & 1.57 & 1.67 \\
\hline & $\begin{array}{c}\text { SSY09 } \\
\text { (pZSack) }\end{array}$ & $\begin{array}{c}\text { LB medium+50 g/l } \\
\text { (Microaerobic, pH 6.3) }\end{array}$ & 0.40 & 0.01 & 0.01 & 0.01 & 0.17 & 1.63 & 97 & 5.72 & 6.84 \\
\hline $\begin{array}{l}\text { Glucose+ } \\
\text { Xylose }\end{array}$ & $\begin{array}{c}\text { SSY09 } \\
\text { (pZSack) }\end{array}$ & $\begin{array}{c}\mathrm{LB} \text { medium }+50 \mathrm{~g} / \mathrm{l} \\
\text { (Microaerobic, pH 6.3) }\end{array}$ & 0.64 & 0.01 & 0.00 & 0.00 & 0.04 & 1.61 & 85 & 5.43 & 14.94 \\
\hline
\end{tabular}

${ }^{a}$ Growth condition in the fermentor is described in materials and method section.

$\mathrm{b} \%$ Theoretical yield of ethanol was calculated by considering theoretical maximum yield of $2 \mathrm{mmol}$ of ethanol per mmol of glucose and $1.67 \mathrm{mmol}$ of ethanol per mmol of xylose as $100 \%$.

${ }^{c}$ Maximum specific ( $\mathrm{mmol}$ ethanol per gram of cells per hour) and volumetric ( $\mathrm{mmol}$ per liter of culture per hour) productivity of ethanol were calculated by accounting the interval at which maximum substrates were consumed and maximum products and cell biomass were formed.

We further tested utilization of mixture of glucose and xylose at $25 \mathrm{~g} / \mathrm{l}$ each under micro-aerobic condition and found complete utilization of sugars in $55 \mathrm{hrs}$ (Figure 6B). As evident from the fermentation profile, glucose was the preferred substrate and got utilized first in $15 \mathrm{~h}$ followed by xylose utilization in next $40 \mathrm{~h}$. Ethanol yield from glucose and xylose was close to $0.43 \mathrm{~g}$ per $\mathrm{g}$ sugar ( $85 \%$ of the maximum theoretical yield) and ethanol was produced at the rate of $14.94 \mathrm{mmol} / \mathrm{l} / \mathrm{h}(0.7 \mathrm{~g} / \mathrm{l} / \mathrm{h})$ during glucose utilization phase and $8.17 \mathrm{mmol} / \mathrm{l} / \mathrm{h}$ $(0.38 \mathrm{~g} / \mathrm{l} / \mathrm{h})$ during xylose utilization phase (Figure $6 \mathrm{~B})$. This rate of ethanol production from mixture of glucose and xylose was close to that of- recombinant E. coli KO11 strain that produced ethanol at overall $0.34 \mathrm{~g} / \mathrm{l} / \mathrm{h}$ from mixture of $10 \mathrm{~g} / \mathrm{l}$ glucose and $40 \mathrm{~g} / \mathrm{l}$ xylose [15] and at $0.72 \mathrm{~g} / \mathrm{l} / \mathrm{h} \mathrm{h}$ in the first $48 \mathrm{~h}$ from mixture of $70 \mathrm{~g} / \mathrm{l}$ glucose and $30 \mathrm{~g} / \mathrm{l} / \mathrm{h}$ xylose of fermentation [16]. None of the reports published before for the engineered $E$. coli without the foreign genes demonstrated utilization of mixture of glucose and xylose $[7,8]$.

The E. coli SSY09(pZSack) strain engineered for ethanol production in this study certainly has advantage over the other engineered $E$. coli strains such as KO11 for not having any foreign genes responsible for ethanol production. E. coli $\mathrm{KO} 11$ has been found to lose its ethanologenicity progressively when cultivated on hemicellulosic sugars in the chemostat culture, possibly due to the genetic instability [17]. Since E. coli SSY09(pZSack) does not have any foreign genes for ethanol production, its ethanologenic property is expected to be stable for much longer generation and therefore this strain should be considered for further studies to evaluate ethanol production from lignocellulosic hydrolysates.

\section{Conclusions}

We replaced promoter of pyruvate dehydrogenase operon $(\mathrm{PDH})$ in $E$. coli with promoters of various genes expressed under anaerobic condition and shown that PDH expression and ethanol yield was maximum under anaerobic condition when its promoter was replaced with gapA promoter. Deletion of pathways for competing products further increased the ethanol yield. However, there was significant drop in cell growth rate. Modulating expression of acetate kinase helped restoring 


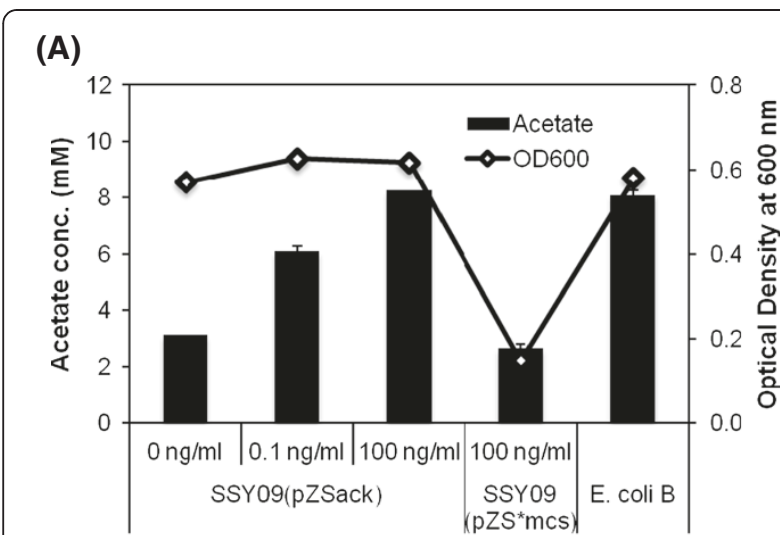

(B)

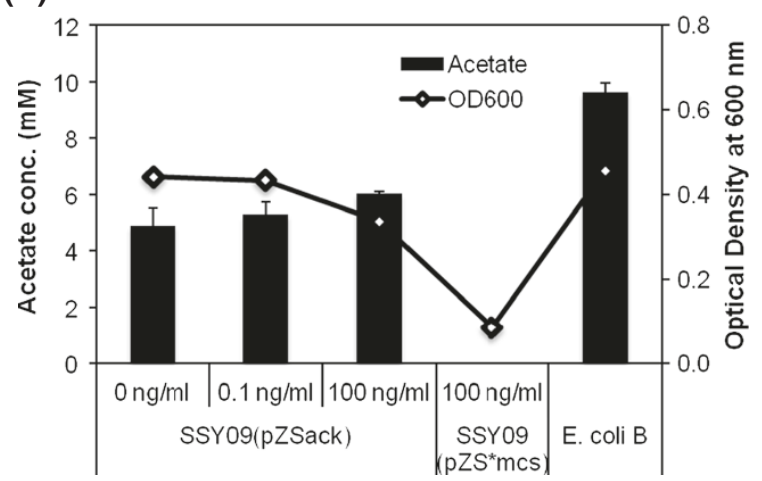

Figure 3 Improvement in cell growth upon modulation of expression of ack gene in the engineered SSY09 strain. SSY09 strain having plasmid pZSack was grown in Hungate tube completely filled with defined media $+2.5 \mathrm{~g} / \mathrm{l}$ glucose (A) or $2.5 \mathrm{~g} / \mathrm{l}$ xylose (B) at $37^{\circ} \mathrm{C}$ for $24 \mathrm{hr}$. Acetate kinase expression was induced with $0,0.1,100 \mathrm{ng} / \mathrm{ml}$ of anhydrotetracycline. E. coli B and SSY09 bearing $\mathrm{pZS}^{*} \mathrm{mcs}$ plasmid were used as positive and negative control, respectively. Results indicate improvement in growth of PZSack transformed cells as compared to control plasmid and less acetate production as compared to wild type strain. Strain

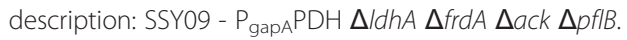

the cell growth rate and improved ethanol productivity significantly. Microaerobic condition further improved the growth rate of the cells on both glucose and xylose. The strain reported here following engineering of endogenous pathway is likely to be genetically more stable and call for further study to evaluate ethanol production from hydrolysate of lignocellulosic biomass.

\section{Methods}

Bacterial strains, plasmids and genetic methods

List of bacterial strains, plasmids and primers used in the study has been provided in Table 1. E. coli DH5 $\alpha$ strain (Invitrogen) was used for performing all the cloning work and E. coli B (Coli Genetic Stock Centre (CGSC), Yale University, USA) was used as parent strain for all the genomic manipulations. Recombinant

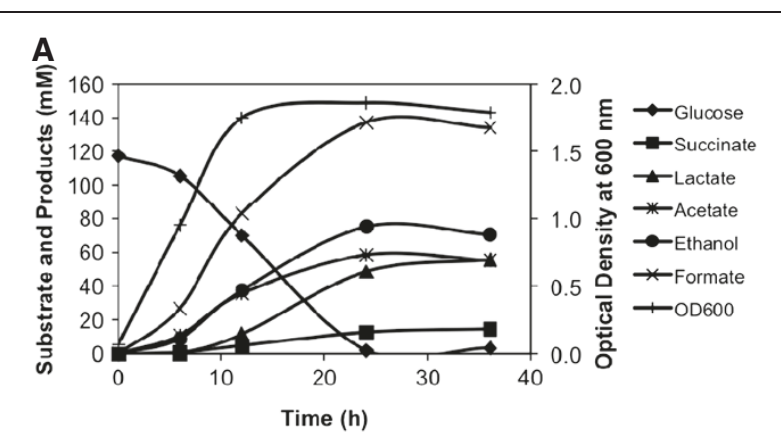

(B)

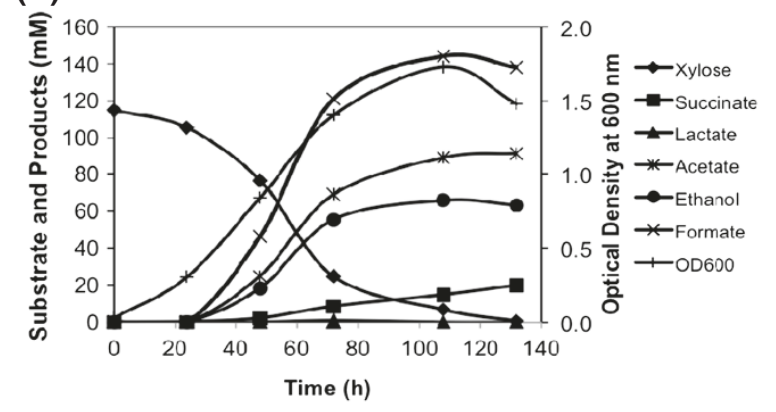

(C)

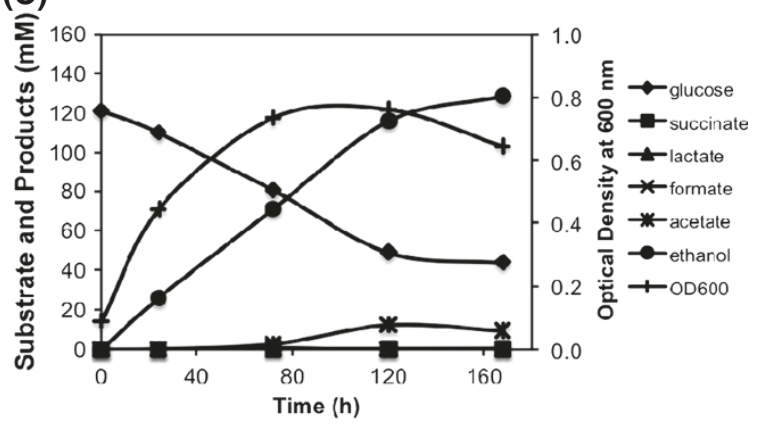

(D)

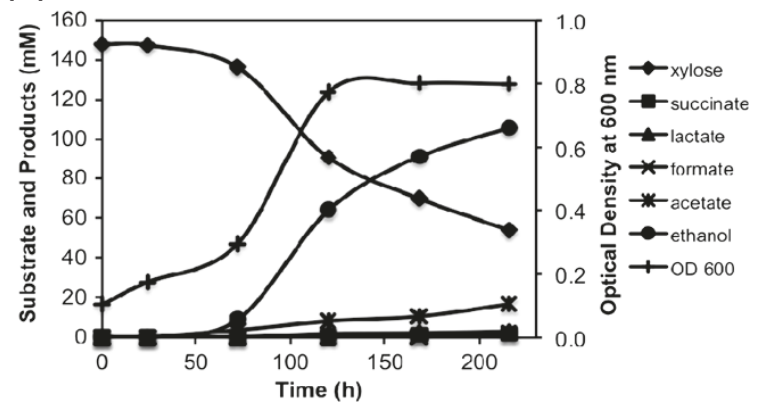

Figure 4 Fermentation profiles of E. coli B (A and B) and SSY09 (pZSack) ( $C$ and $D)$ grown in the bioreactor in defined medium with glucose ( $A$ and $C$ ) and xylose ( $B$ and $D)$ as carbon source. Competing products of ethanol are produced at significant level during fermentation of both glucose and xylose in E. coli B while SSY09(pZSack) primarily produced ethanol. SSY09(pZSack) $\mathrm{P}_{\text {gapA }} \mathrm{PDH} \Delta / d h A \Delta$ frdA $\triangle a c k \Delta p f l B$ (pZSack). 


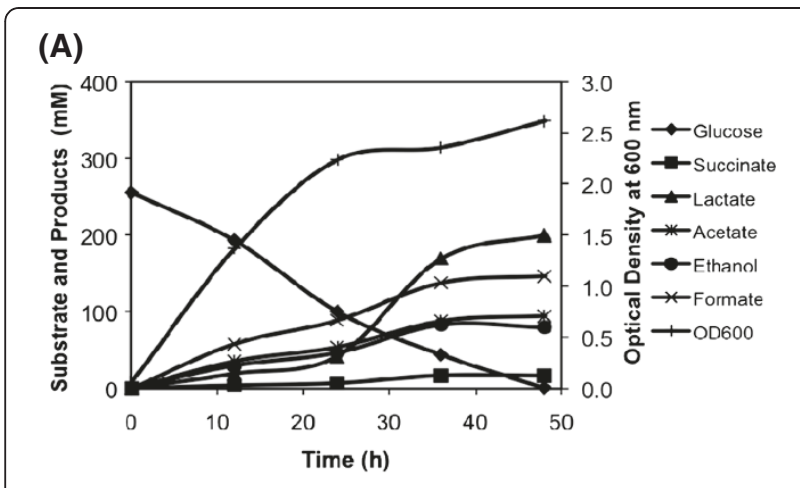

(B)

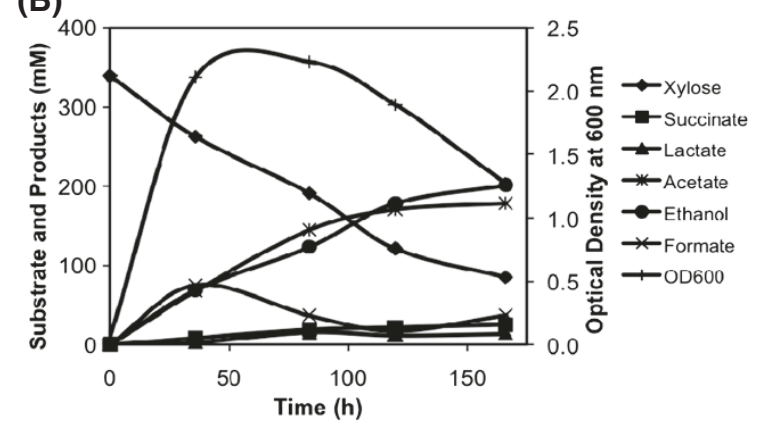

(C)

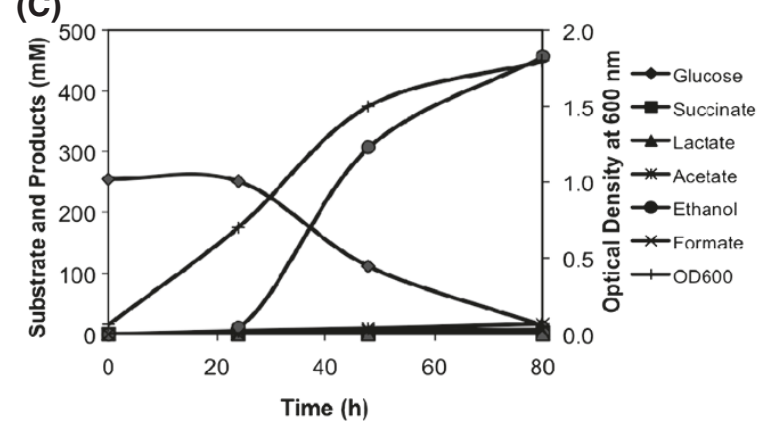

(D)

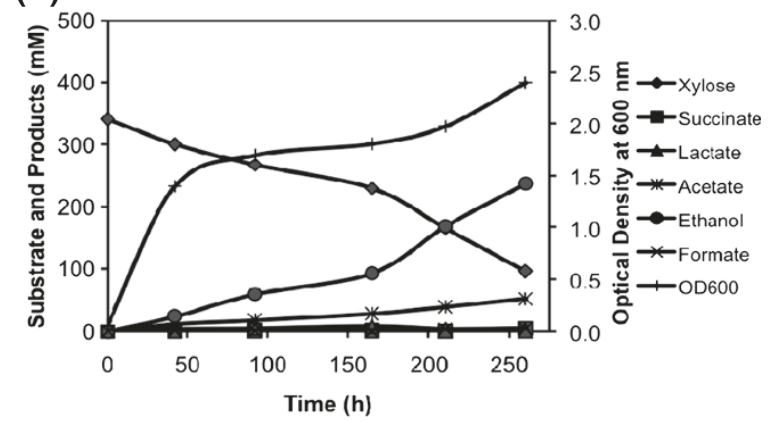

Figure 5 Fermentation profile of E. coli B (A and B) and SSY09 (pZSack) (C and D) grown in the bioreactor in complex medium with glucose ( $A$ and $C$ ) and xylose ( $B$ and $D)$ as carbon source. Only small fraction of carbon has been used by the E. coli B cells to produce ethanol. SSY09(pZSack) strain utilized glucose and produced ethanol at a significantly high rate. Xylose utilization rate, however, was still slow. Strain description: SSY09(pZSack) - P gapAPDH $\triangle$ IdhA $\triangle$ frdA $\triangle$ ack $\triangle p f l B$ (pZSack).
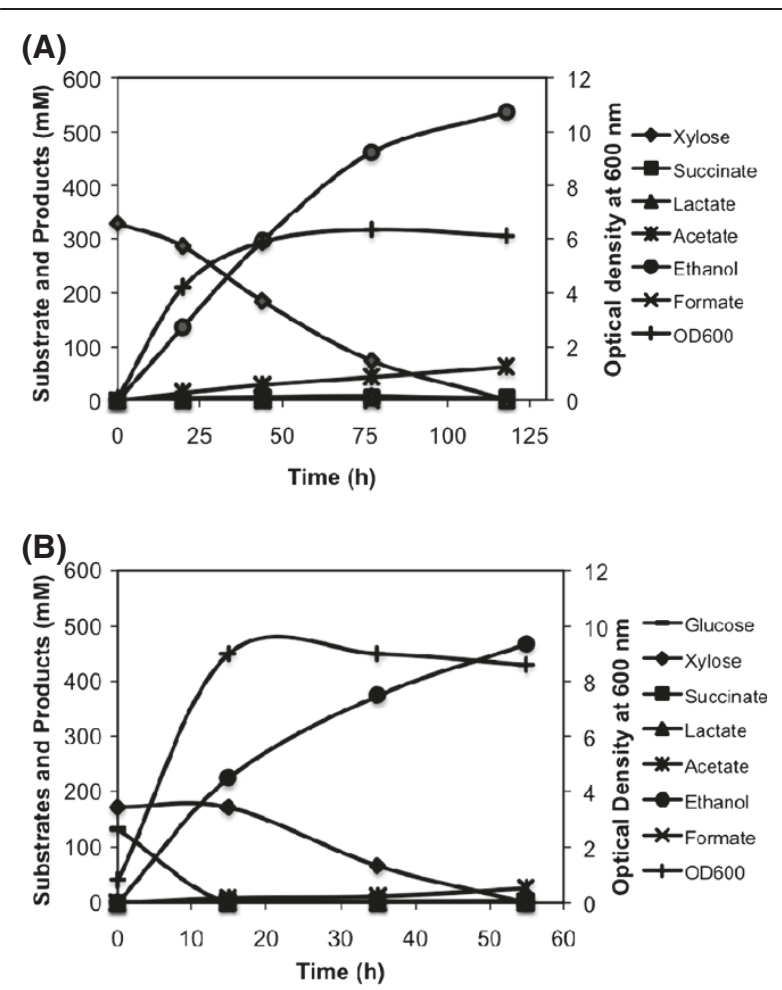

Figure 6 Fermentation profile of SSY09(pZSack) strain grown under microaerobic condition in the bioreactor in complex medium with (A) xylose and (B) mixture of glucose and xylose as carbon source. The profile indicated efficient utilization of xylose and mixture of glucose and xylose under microaerobic condition and production of ethanol with high yield and productivity. Strain description: SSY09(pZSack) - $\mathrm{P}_{\text {gapA }} \mathrm{PDH} \Delta / d h A \Delta$ frdA $\Delta$ ack $\Delta$ pflB (pZSack).

DNA techniques were performed according to standard procedures [18]. Restriction endonuclease and T4 DNA ligase were procured from New England Biolabs and DNA purification was performed using Qiagen kit. Custom oligonucleotides (primers) were synthesized from Sigma-Aldrich for PCR amplifications. DNA fragments were amplified by Phusion High Fidelity polymerase (Finnzymes) for cloning and template preparation for homologous recombination and Taq DNA polymerase (Bangalore Genei) was used for performing verification PCR of the engineered strains. Plasmids pKD4, pKD46 and pCP20 (CGSC, USA) were used as the source of FRT-kan-FRT fragment, lambda Red recombinase and flippase, respectively, for performing genetic manipulation.

For replacement of $\mathrm{PDH}$ operon promoter in the $E$. coli $\mathrm{B}$ genome, following procedure was adopted. FRTkan-FRT sequence from pKD4 was amplified using FRTkan-FRT-F and FRT-kan-FRT-R primers (Table 1), digested with EcoRI and BamHI and ligated to the corresponding restriction endonuclease sites of pUC19 plasmid to generate the plasmid pSSY01. Promoters of the 
genes $l d h A$, adhE, frdA, gapA and $p f l B$, along with their corresponding ribosome binding sites, were amplified from $E$. coli B genomic DNA using their respective primers listed in Table 1. The PCR products obtained were digested with BamHI and HindIII and ligated at the 3' end of FRT-kan-FRT in pSSY01 to produce plasmids pSSY02-06 (Table 1). A 45 bases homologous sequence for -202 to $-157 \mathrm{bp}$ upstream of $p d h R$ coding region of $\mathrm{PDH}$ operon was added to the 20 bases of 5 ' end of FRT-kan-FRT sequence to design primer $\mathrm{H} 1$ and a 45 bases homologous sequence corresponding to +1 to +45 coding region of ace $\mathrm{E}$ of $\mathrm{PDH}$ operon was added to 20-22 bases of 3' end of each promoter to obtain primer $\mathrm{H} 2$ (Table 1). PCR was performed with the $\mathrm{H} 1$ and $\mathrm{H} 2$ primers and corresponding plasmid pSSY02-06 as template under following conditions: $98^{\circ} \mathrm{C}$ for $2 \mathrm{~min}$, followed by 30 cycles of denaturation at $98^{\circ} \mathrm{C}$ for $15 \mathrm{sec}$, annealing at $59^{\circ} \mathrm{C}$ for $15 \mathrm{sec}$, extension at $72^{\circ} \mathrm{C}$ for $2 \mathrm{~min}$ and a final extension at $72^{\circ} \mathrm{C}$ for $10 \mathrm{~min}$. The PCR product was gel eluted, digested with DpnI, re-purified and electroporated (2.5 KV, $25 \mu \mathrm{F}$ and $200 \Omega$ ) into E. coli B carrying pKD46 (grown in $\mathrm{LB}$ broth with $1 \mathrm{mM} \mathrm{L}$-arabinose at $30^{\circ} \mathrm{C}$ till $\mathrm{OD}_{600 \mathrm{~nm}}$ reaches $\sim 0.3-0.4$ ) to replace the promoter, RBS and pdhR gene of pyruvate dehydrogenase (PDH) operon with the heterologous promoter [19]. Transformants were selected on kanamycin LB-agar plates. The engineered strains (SSY01-05) (Table 1) were verified for the $\mathrm{PDH}$ promoter replacement by performing two sets of colony PCR, one set using v-PDH-F (-372 bp upstream of $p d h R)$ and $\mathrm{v}-\mathrm{PDH}-\mathrm{R}(+163 \mathrm{bp}$ downstream of start of coding region of $a c e F$ ) primers to verify native promoter deletion, and second set using forward primer of the heterologous promoter and V-PDH-R to verify introduction of heterologous promoter (data not shown). Before further manipulation, the kanamycin resistance marker gene was removed from the chromosome of the selected strain with the help of FLP recombinase by using the temperature sensitive helper plasmid, pCP20 [19].

Host gene deletions were achieved through P1 transduction method [20] using the single gene knockout Keio strains from CGSC, Yale University, USA [21]. The kanamycin resistant marker gene was removed as described above and the resultant strain was used for sequential rounds of gene knockout.

For the construction of pZSack plasmid, the multiple cloning site (MCS) of pET28a(+) (Novagen) was amplified using pET28mcs-F and pET28mcs-R primers and cloned in pZSblank plasmid [11] to obtain pZS*mcs. The ackA gene encoding acetate kinase was amplified from $E$. coli B genome using pZS-ack-F and pZS-ack-R primers, digested with $\mathrm{BamHI}$ and $\mathrm{SalI}$ and the resultant fragment was ligated into the BamHI-SalI sites of pZS*mcs to produce pZSack. The pZSack plasmid was then electroporated into SSY09 for enhancement of growth rate.

\section{Media and culture conditions}

Bacterial strains were grown in either LB medium or Morpholino-propanesulfonic (MOPS) defined medium [22]. Antibiotics were added as appropriate with ampicillin at $50 \mu \mathrm{g} / \mathrm{ml}$, kanamycin at $30 \mu \mathrm{g} / \mathrm{ml}$ and chloramphenicol at $34 \mu \mathrm{g} / \mathrm{ml}$. For checking production of metabolites by the engineered strains in the tube, the strains were grown overnight at $37^{\circ} \mathrm{C}$ on LB agar plates containing relevant antibiotic and an isolated colony was inoculated in Hungate tube filled until brim $(17.5 \mathrm{ml})$ with 1X MOPS or LB medium supplemented with antibiotics and desired sugar as carbon source. In the study where engineered strains were transformed with pZSack or pZS*mcs plasmid, the cells were grown in the Hungate tube filled with media containing $0,0.1$ or $100 \mathrm{ng} / \mathrm{ml}$ of anhydrotetracycline as inducer and $34 \mu \mathrm{g} / \mathrm{ml}$ of chloramphenicol as antibiotic. The tubes were incubated at $37^{\circ} \mathrm{C}$ under rotating condition and harvested at different intervals. The optical density of the grown culture was recorded at $600 \mathrm{~nm}$ and supernatant was saved for metabolite analysis via HPLC as mentioned in analytical methods section.

The engineered strains were cultivated in the bioreactor to evaluate their performance under controlled environment at various stages of manipulation. Primary culture was prepared by incubating an isolated colony from agar plate into $17.5 \mathrm{ml}$ MOPS medium containing $2.5 \mathrm{~g} / \mathrm{l}$ glucose in Hungate tube for $24 \mathrm{hr}$ at $37^{\circ} \mathrm{C}$. In case of SSY09 where ack and pflB genes were deleted, primary culture was adapted to anaerobic condition in $100 \mathrm{ml}$ medium in a $250 \mathrm{ml}$ flask containing $2.5 \mathrm{~g} / \mathrm{l}$ glucose or $\mathrm{xy}-$ lose for $48 \mathrm{hr}$ at $37^{\circ} \mathrm{C}$ in anaerobic chamber (Bactron II, Shel Lab). Appropriate volume of the culture to achieve initial $\mathrm{OD}_{600 \mathrm{~nm}}$ of 0.05 in the bioreactor was centrifuged at $4000 \mathrm{rpm}$ for $4 \mathrm{~min}$ and re-suspended in fresh medium. The culture was inoculated in one of the six $0.5 \mathrm{~L}$ vessels of Biostat $\mathrm{Q}$ plus fermentor (Sartorius) containing $350 \mathrm{ml}$ of MOPS or LB medium having appropriate amount of sugar. The vessels were controlled independently at $37^{\circ} \mathrm{C}, 300 \mathrm{rpm}$ and $\mathrm{pH}$ 6.8. High purity Argon gas was purged in the medium to create anaerobic environment at a rate of $0.02 \mathrm{~L} / \mathrm{min}$. In case of fermentation under microaerobic condition, compressed air was passed in the headspace of the vessel at the rate of $0.02 \mathrm{~L} / \mathrm{min}$ at which dissolved oxygen probe demonstrated zero reading throughout the fermentation. Samples collected from fermentor vessels at various time intervals were used to calculate cell growth, substrate utilization and product synthesis. All fermentations were performed in duplicate and data in the figures represented average of two bioreactor runs. 


\section{Enzyme assay}

To check the activity of PDH enzyme under anaerobic conditions, engineered E. coli B strains with heterologous PDH promoter along with wild type strain as control were grown in Hungate tubes filled with MOPS medium $+2.5 \mathrm{~g} / \mathrm{l}$ glucose for 12, 18, 24 and $36 \mathrm{hrs}$ at $37^{\circ} \mathrm{C}$. Cells were harvested by centrifugation $(5 \mathrm{~min}$, $5000 \mathrm{rpm}$ ), washed twice with $9 \mathrm{~g} / \mathrm{l} \mathrm{NaCl}$ and stored as cell pellets at $-20^{\circ} \mathrm{C}$. Cell pellets were resuspended in 0.1 $\mathrm{M}$ potassium phosphate buffer $\left(\mathrm{pH}\right.$ 8.0) to obtain $\mathrm{OD}_{600}$ of 10 and were permeabilized with chloroform. The reaction was set-up in $1 \mathrm{ml}$ in the cuvette containing $50 \mathrm{mM}$ potassium phosphate buffer $(\mathrm{pH} 8.0), 2.0 \mathrm{mM}$ sodium pyruvate, $2.5 \mathrm{mM} \mathrm{NAD}{ }^{+}, 0.2 \mathrm{mM}$ thiamine pyrophosphate, $1.0 \mathrm{mM} \mathrm{MgCl}_{2}, 0.13 \mathrm{mM} \mathrm{CoA}, 2.6 \mathrm{mM}$ cysteine hydrochloride. Permeabilized cells $(25 \mu \mathrm{l})$ were added to start the reaction and the pyruvate dehydrogenase activity was measured by detecting change in absorbance at $340 \mathrm{~nm}$ (Ultrospec 3100 pro, Amersham Biosciences) [23]. Substrate blank where no sodium pyruvate was added served as control. Enzyme activity was calculated as nmol NADH formed $/ \mathrm{min} / \mathrm{mg}$ of cell protein. A protein content of $50 \%$ (wt/wt) with respect to dry cell mass was assumed in these calculations.

\section{Analytical methods}

Extracellular metabolites of the grown culture were determined as follows. Culture of the grown cells was centrifuged at 13,200 rpm for $5 \mathrm{~min}$. The aqueous supernatant was filtered and used for HPLC analysis. The metabolite separation was achieved using the HPLC system (Agilent technologies) attached with Aminex HPX-87 H anion exchange column (Bio-Rad). The filtered and degassed mobile phase ( $4 \mathrm{mM} \mathrm{H}_{2} \mathrm{SO}_{4}$ ) was used at a constant rate of $0.3 \mathrm{ml} / \mathrm{min}$ with column and RI detector temperatures maintained at $40^{\circ} \mathrm{C}$ and $35^{\circ} \mathrm{C}$, respectively. Standards of the metabolites (Absolute Standards, USA) at $1 \mathrm{~g} / \mathrm{l}$ were separated on HPLC column and areas obtained were used to calculate metabolite concentration in the text samples. Cell density was measured at an optical density $600 \mathrm{~nm}\left(\mathrm{OD}_{600}\right)$ in a spectrophotometer (BioRad). Dry cell mass was calculated by drying cell pellets of defined $\mathrm{OD}_{600}$ at $75^{\circ} \mathrm{C}$ in oven for $20 \mathrm{hr}$. The $\mathrm{OD}_{600}$ of 1.0 corresponded to $0.56 \mathrm{mg}$ dry mass per $\mathrm{ml}$ of culture.

The values obtained for cell biomass, substrate utilization and product synthesis were used for calculation of biomass and product yields $(\mathrm{mmol} / \mathrm{mmol}$ substrate), specific productivity ( $\mathrm{mmol} /$ gcell/h) and volumetric productivity $(\mathrm{mmol} / \mathrm{L} / \mathrm{h})$. For calculating biomass yield we used a molecular formula of cells as $\mathrm{CH}_{1.9} \mathrm{O}_{0.5} \mathrm{~N}_{0.2}$ with an average molecular weight of $24.7[11]$.

\section{Competing interest}

The authors declare that they have no competing interests.

\section{Authors' contributions}

NM carried-out all the promoter replacements, NM and AJM performed phage transduction for creating deletion mutants, DP and NM performed fermentation studies, PSS provided intellectual input for the study, SSY conceived and coordinated the study and SSY and NM drafted the manuscript. All authors read and approved the final manuscript.

\section{Acknowledgements}

We are thankful to Dr. Ramon Gonzalez for providing pZSblank plasmid. The study was supported by the financial grants from Department of Biotechnology and Department of Science and Technology, Government of India. NM was supported by the fellowship from Council of Scientific and Industrial Research.

\section{Author details}

${ }^{1}$ Synthetic Biology and Biofuel Group, International Centre for Genetic Engineering and Biotechnology (ICGEB), Aruna Asaf Ali Marg, New Delhi 110067, India. ${ }^{2}$ Centre for Biotechnology, Jamia Hamdard, Hamdard Nagar, New Delhi 110062, India.

Received: 9 July 2012 Accepted: 29 October 2012

Published: 4 November 2012

\section{References}

1. Hansen J, Nazarenko L, Ruedy R, Sato M, Willis J, Del Genio A, Koch D, Lacis A, Lo K, Menon S, et al: Earth's energy imbalance: confirmation and implications. Science 2005, 308:1431-1435.

2. Lynd LR, Weimer PJ, van ZyI WH, Pretorius IS: Microbial cellulose utilization: fundamentals and biotechnology. Microbiol Mol Biol Rev 2002, 66:506-577.

3. Stephanopoulos $\mathrm{G}$ : Challenges in engineering microbes for biofuels production. Science 2007, 315:801-804.

4. Ingram LO, Aldrich HC, Borges AC, Causey TB, Martinez A, Morales F, Saleh A, Underwood SA, Yomano LP, York SW, et al: Enteric bacterial catalysts for fuel ethanol production. Biotechnol Prog 1999, 15:855-866.

5. Kuyper M, Toirkens MJ, Diderich JA, Winkler AA, van Dijken JP, Pronk JT: Evolutionary engineering of mixed-sugar utilization by a xylosefermenting Saccharomyces cerevisiae strain. FEMS Yeast Res 2005, 5:925-934.

6. Zhang M, Eddy C, Deanda K, Finkelstein M, Picataggio S: Metabolic Engineering of a Pentose Metabolism Pathway in Ethanologenic Zymomonas mobilis. Science 1995, 267:240-243.

7. Kim Y, Ingram LO, Shanmugam KT: Construction of an Escherichia coli K12 mutant for homoethanologenic fermentation of glucose or xylose without foreign genes. Appl Environ Microbiol 2007, 73:1766-1771.

8. Zhou S, Iverson AG, Grayburn WS: Engineering a native homoethanol pathway in Escherichia coli B for ethanol production. Biotechnol Lett 2008, 30:335-342.

9. Hasona A, Kim Y, Healy FG, Ingram LO, Shanmugam KT: Pyruvate formate lyase and acetate kinase are essential for anaerobic growth of Escherichia coli on xylose. J Bacteriol 2004, 186:7593-7600.

10. Cassey B, Guest JR, Attwood MM: Environmental control of pyruvate dehydrogenase complex expression in Escherichia coli. FEMS Microbiol Lett 1998, 159:325-329.

11. Yazdani SS, Gonzalez R: Engineering Escherichia coli for the efficient conversion of glycerol to ethanol and co-products. Metab Eng 2008, 10:340-351.

12. Cripps RE, Eley K, Leak DJ, Rudd B, Taylor M, Todd M, Boakes S, Martin S, Atkinson T: Metabolic engineering of Geobacillus thermoglucosidasius for high yield ethanol production. Metab Eng 2009, 11:398-408.

13. Diaz-Ricci JC, Regan L, Bailey JE: Effect of alteration of the acetic acid synthesis pathway on the fermentation pattern of Escherichia coli. Biotechnol Bioeng 1991, 38:1318-1324.

14. Lam VM, Daruwalla KR, Henderson PJ, Jones-Mortimer MC: Proton-linked D-xylose transport in Escherichia coli. J Bacteriol 1980, 143:396-402.

15. Takahashi CM, Takahashi DF, Alterthum F: Fermentation of sugar cane bagasse hemicellulosic hydrolysate and sugar mixtures to ethanol by 
recombinant Escherichia coli KO11. World J Microbiol Biotechnol 2000, 16:829-834.

16. Lau MW, Gunawan C, Balan V, Dale BE: Comparing the fermentation performance of Escherichia coli KO11, Saccharomyces cerevisiae 424A (LNH-ST) and Zymomonas mobilis AX101 for cellulosic ethanol production. Biotechnol Biofuels 2010, 3:11.

17. Dumsday GJ, Zhou B, Yaqin W, Stanley GA, Pamment NB: Comparative stability of ethanol production by Escherichia coli KO11 in batch and chemostat culture. J Ind Microbiol Biotechnol 1999, 23:701-708.

18. Sambrook J, Fritsch EF, Maniatis T: Molecular Cloning, A Laboratory Manual. secondth edition. Cold Spring Harbour, NY: Cold Spring Harbor Laboratory Press; 1989.

19. Datsenko KA, Wanner BL: One-step inactivation of chromosomal genes in Escherichia coli K-12 using PCR products. Proc Natl Acad Sci U S A 2000, 97:6640-6645.

20. Miller JH: Experiments in Molecular Genetics. Cold Spring Harbor, NY: Cold Spring Harbor Laboratory Press; 1972

21. Baba T, Ara T, Hasegawa M, Takai Y, Okumura Y, Baba M, Datsenko KA, Tomita M, Wanner BL, Mori H: Construction of Escherichia coli K-12 in-frame, single-gene knockout mutants: the Keio collection. Mol Syst Biol 2006, 2:2006-2008.

22. Neidhardt FC, Bloch PL, Smith DF: Culture medium for enterobacteria. J Bacteriol 1974, 119:736-747.

23. Danson MJ, Hooper EA, Perham RN: Intramolecular coupling of active sites in the pyruvate dehydrogenase multienzyme complex of Escherichia coli. Biochem J 1978, 175:193-198.

doi:10.1186/1475-2859-11-145

Cite this article as: Munjal et al: Modulation of endogenous pathways enhances bioethanol yield and productivity in Escherichia coli. Microbial Cell Factories 2012 11:145.

\section{Submit your next manuscript to BioMed Central and take full advantage of:}

- Convenient online submission

- Thorough peer review

- No space constraints or color figure charges

- Immediate publication on acceptance

- Inclusion in PubMed, CAS, Scopus and Google Scholar

- Research which is freely available for redistribution 